\title{
BMJ Open Multidimensional analysis of factors responsible for the low prevalence of ambulatory peritoneal dialysis in Germany (MAU-PD): a cross-sectional Mixed-Methods Study Protocol
}

Nadine Scholten, ${ }^{1}$ Tim Ohnhaeuser, ${ }^{1}$ Isabell Schellartz, ${ }^{1}$ Gero von Gersdorff, ${ }^{2}$ Martin Hellmich, ${ }^{3}$ Ute Karbach, ${ }^{1}$ Holger Pfaff, ${ }^{1}$ Christina Samel, ${ }^{3}$ Stephanie Stock, ${ }^{4}$ Katherine Rascher, ${ }^{2}$ Thomas Mettang $^{5}$

\section{ABSTRACT}

Introduction Patients with end-stage kidney failure can be treated either by transplant or by dialysis, which can be administered as haemodialysis (HD) or peritoneal dialysis (PD). Although they are equivalent therapeutic options in terms of mortality, the percentage of patients in Germany treated with PD is currently very low $(\sim 6 \%)$ compared with other countries. The aim of our study is to analyse the factors behind this percentage and their relevance to the choice of dialysis treatment in Germany. This includes analyses of regional disparities in the provision of care for dialysis patients as well as the evaluations of costs and the influence of reimbursement structures. This approach should provide further insights to explain the variation in the usage of PD and HD and will help to define starting points for future interventions.

Methods and analysis A mixed-methods approach will be applied to several data sources, including administrative data (ambulatory physicians' claim data, statutory health insurance claim data), quality assurance data from one of the largest German dialysis providers Kuratorium für Dialyse $(\mathrm{KfH})$ and qualitative and quantitative survey data (patients, nephrologists and dialysis nurses). Qualitative data will be analysed content-analytically. Based on the quantitative data, multivariable analyses will be performed and, where possible, hierarchical models will be tested. This multidimensional approach will enable us to account for the different factors influencing the penetration of PD in Germany.

Ethics and dissemination Ethics approval (17-299) has been obtained from the Ethics Committee of the Medical Faculty of the University of Cologne on 25 April 2018. National and international dissemination will be accomplished by informing healthcare practitioners, patients and professional organisations and other stakeholders via conferences, scientific and non-scientific publications and seminars. Trial registration number DRKS00012555; Pre-Results. permitted under CC BY-NC. No commercial re-use. See rights and permissions. Published by BMJ.

For numbered affiliations see end of article.

Correspondence to Dr Nadine Scholten; Nadine.Scholten@uk-koeln.de

\section{INTRODUCTION}

Haemodialysis (HD) and peritoneal dialysis (PD) are the main renal replacement therapies for patients with end-stage renal disease. HD is predominantly administered in

\section{Strengths and limitations of this study}

- The study MAU-PD focuses on the patient perspective as well as examining the issue at the provider level.

- The mixed-methods approach (qualitative and quantitative data) and the combination of primary and secondary data sources allow a multidimensional view of the utilisation performance of the different dialysis modalities in Germany.

- Analyses based on administrative data facilitate an unbiased description of the current care situation.

- Focus groups and interviews give greater insight into the topic and will provide the basis for questionnaire development.

- The claims data cover $90 \%$ of the German dialysis population at most, as there are no accessible data on the privately-insured sector of the population.

ambulant dialysis units, while PD is a primarily home-based treatment option. According to the national annual report on the quality of dialysis published in 2016, there are about 75000 chronic dialysis patients in Germany, with an overall PD rate of 5.9\%. ${ }^{1}$ Of patients new to dialysis in 2016, 4756 patients began HD and 554 PD treatment, a PD-incidence rate of $11.6 \%{ }^{1}$ International comparison reveals a wide variation in PD proportion. Japan has a rate of only $3 \%$, while PD patients make up about $10 \%$ of dialysis patients in Spain, $19 \%$ in Finland, 20.2\% in Australia, $29.6 \%$ in New Zealand and $73 \%$ in Hong Kong. ${ }^{2-4}$ These wide discrepancies cannot be explained by differences in mortality or contraindications of the patient populations.

In contrast, reimbursement and economic considerations have been highlighted as relevant factors in the predominance of HD 
within a healthcare system. ${ }^{5}$ But this does not explain the regional PD variations within the same healthcare system. $^{6-8}$ The cause, therefore, seems to be multifaceted and attributable to patient, physician and structural factors. ${ }^{9-11}$ The treating physician has a key role, as his or her attitude towards PD has a major influence on the treatment decision. ${ }^{10}{ }^{12}$ Physicians' attitudes are associated with their professional experience and vice versa. Consequently, more PD training for health professionals leads to more patients being treated with PD. ${ }^{13}$ As PD is an ambulatory treatment, it does not play a significant role in nephrologists' medical specialisation training in Germany, which takes place within the hospital setting. ${ }^{14}$ This could be a reason for providers' apparent reluctance to use PD.

Nurses play a crucial role in the management of PD patients by giving technical instruction and motivation. ${ }^{15}$ To successfully implement PD in practice, welltrained nurses are essential. ${ }^{16}$ Therefore, nursing also plays an important role in the considerations regarding the decision between HD and PD.

The number of patients treated with home dialysis is positively influenced by a high number of PD patients at a dialysis centre and negatively influenced by greater HD capacity within the centre. ${ }^{17}$ As long as a centre has high HD capacity, there is a strong incentive to fill this capacity. ${ }^{5}$ The treatment of PD patients requires an infrastructure that meets the special needs of PD patients. Ideally, this includes a nurse specialising in PD to train and support the patient in the self-administration of $\mathrm{PD}$ and to be available in case of emerging problems or complications. ${ }^{14}{ }^{16}$ Developing and maintaining such an infrastructure, when there are only a few PD patients cared for within a dialysis centre, is one major barrier to increasing PD implementation. ${ }^{14}$

PD is often seen as a treatment option for young and relatively healthy patients. Therefore, the increasing age of the dialysis population is frequently regarded as an obstacle to increasing the proportion of PD patients. ${ }^{11819}$ However, the older patients in particular seem to benefit from this therapeutic option, as they do not have to leave their familiar environment. ${ }^{20}$ If patients are asked what therapeutic option they prefer, many of them choose a treatment that can be performed at home. ${ }^{21}$ One finding of the CEAPIR study was that $36 \%$ of the patients questioned had not been informed of the different treatment options regarding dialysis. ${ }^{22}$ This corresponds to the results of the CORETH study, in which almost one-third of the patients stated that the treatment decision had been made by their physician. ${ }^{23}$

The low PD rate in Germany seems to be a result of many influencing factors at different levels (patients, physicians, nurses and structure). There are no significant differences in mortality between $\mathrm{HD}$ and PD patients, ${ }^{24}$ but PD patients report higher quality of life and a more self-determined life. ${ }^{25}{ }^{26}$ As PD is also more cost-effective, ${ }^{27}$ it is important to know more about the reasons for the low PD rate in Germany. Therefore,

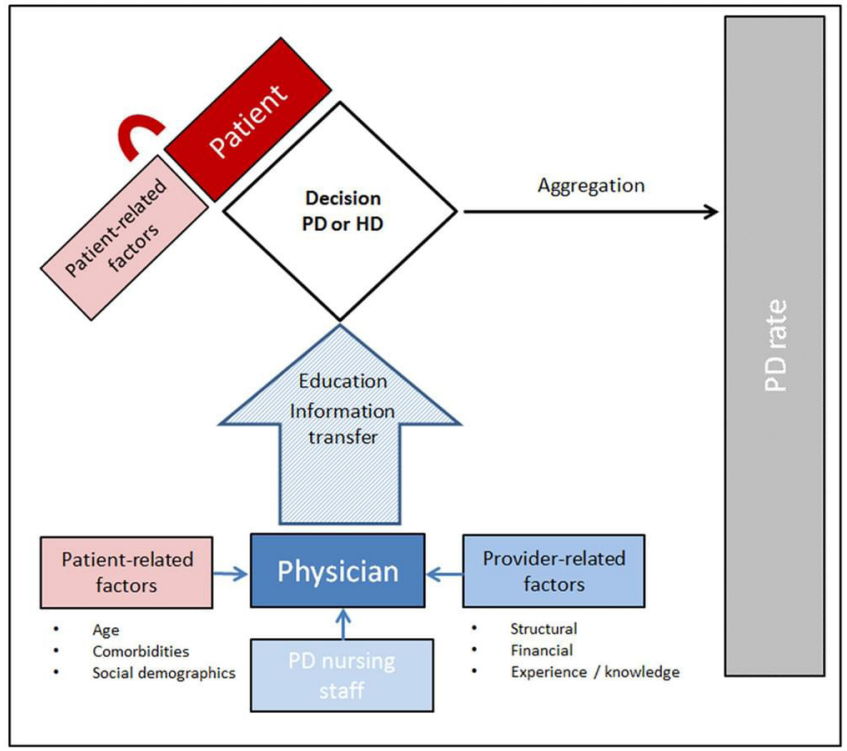

Figure 1 Influencing factors on the decision for or against peritoneal dialysis.

the aim of our study is to analyse the multifactorial effects regarding the provider and structural levels, and their relevance to the performance of PD in Germany. The analysis of regional provisions of care for dialysis patients, as well as the examination of costs and type of costs, offers further insights. The aim is to explain the variation in the use of $\mathrm{PD}$ and $\mathrm{HD}$ and to fully illuminate the current dialysis situation in Germany.

\section{METHODS AND ANALYSIS}

The mixed-methods study will be based on several data sources, including administrative data, quality-assurance data and qualitative and quantitative survey data. By using this multidimensional approach, it will be possible to account for the different factors influencing the performance of PD in Germany. Figure 1 represents possible influencing stakeholders and factors on the aggregated PD rate. The decision for PD or HD is the result of the patient-physician interaction, influenced by patient-related and provider-related factors. Besides patient-related factors like age, comorbidities or social demographics, on the provider side, structural, financial, knowledge-based and experience-based variables may have an impact. Figure 1 gives an overview of possible influencing factors on the decision for or against PD.

The study focuses on the following hypotheses:

- The decision for the dialysis modality (HD vs PD) is influenced by:

- H1: patient-related factors (eg, age, level of information).

- H2: provider-related factors (eg, training, experience, practice structure, organisational behaviour). 


\section{Administrative data analysis}

To get a greater insight into the current treatment of dialysis patients regarding $\mathrm{HD}$ and $\mathrm{PD}$, the following datasets will be analysed:

1. Ambulatory physicians' claim data (Zentralinstitut für die Kassenärztliche Versorgung in Deutschland (ZI) / Central Research Institute of Ambulatory Health Care) from around 86000 dialysis patients covered by German statutory health insurance.

2. Statutory health insurance claim data (DAK-Gesundheit and Siemens Betriebskrankenkasse) covering around seven million insured patients in Germany.

3. Clinical and medical quality data from one of the largest German dialysis providers (Quality in Nephrology [QiN] registry of KfH-Kuratorium für Dialyse und Nierentransplantation e.V./KfH Board of Trustees for Dialysis and Kidney Transplantation, $\mathrm{n}=205$ dialysis centres, treating around 15000 patients per year).

Ambulatory physicians' claim data will be analysed on a regional level, to account for regional differences in the preponderance of HD and PD. In addition to patient characteristics, this hierarchic dataset has further information at the provider level and can be enriched by data at the regional level. The data at the patient level include, for example, age, sex, comorbidities and treatment by other ambulatory physicians. At the provider level, it is possible to account for the number of physicians within the dialysis centre, number of patients, clinical characteristics of the patient base or linkage to other healthcare providers. Structural data at the regional level include urbanisation, socio-regional data such as unemployment rate, household income, number of nursing cases, and ambulatory and stationary treatment opportunities. Hierarchical multilevel modelling will allow us to account for clustering of data at the different levels, making it possible to identify influencing factors. The uniqueness of this dataset lies in the clustering of the data at the provider level, giving greater insight into its relevance.

An economic analysis comparing HD and PD patients will be performed on the basis of claims data of about seven million insured individuals in Germany. By propensity score, matching HD and PD patients retrospectively over a 5-year time frame, the study will explore differences in costs, service use, hospitalisation and survival.

A third dataset (QiN registry), containing routine medical monitoring and quality data from one of the largest German dialysis providers, will provide additional insight into the provision of $\mathrm{HD}$ and PD. This dataset includes supplementary clinical measures, such as the nutritional or transplant status of the patient. The clustering of the data at the provider level will allow further insights into the organisational structure influencing the provision of $\mathrm{HD}$ and $\mathrm{PD}$.

Appropriate precautionary measures will be taken with regard to the analysis of the claims data. The Good Practice of Secondary Data Analysis guidelines and recommendations ${ }^{28}$ will be followed, as the data were collected for reimbursement, not for scientific reasons. This might be a threat to the validity of the data and has to be addressed.

\section{Qualitative data collection and analysis}

To identify factors that influence patients' decisions on dialysis modality, 12 hypothesis-generating guided interviews will be performed (semi-structured, six HD patients and six PD patients). By purposefully selecting the interviewees, we will consider relevant criteria such as age, sex and education. Due to the focus on decision making, interviewees will be selected from patients who started dialysis within the last 2 years. The number of interviews will be adapted with respect to the saturation point. Participants will be recruited via regional patient organisations. Two focus groups with nephrologists (six to eight persons each) and two with dialysis nurses (head nurse and team, six to eight persons each) will generate greater insight into the providers' situation and their motivation to provide HD or PD. Providers will be recruited at specialists' conventions and by phone; the focus groups will then take place either during a specialists' conference or at our institute. As an incentive, participating physicians and nurses, as well as patients, will receive financial compensation. The interviews and focus groups will be digitally recorded and guided by scientific standards, transcribed and pseudonymised. Content analysis will be conducted afterwards, and categories will be built in workshops together with the research team. MAXQDA 12 software will support the coding and analysis of the text material. Analysis will follow Kuckartz's content-structuring approach. ${ }^{29}$ In keeping with an exploratory sequential design, the development of the questionnaires for the patients, dialysis physicians and nurses (head nurse and PD nurses) will be based on the qualitative results and followed by a pretest.

\section{Quantitative data collection and analysis}

As part of the study, dialysis patients, physicians (nephrologists) and nurses (head nurse and PD-nurses) will be asked to fill out a written (postal) survey. The aim of this survey and the following quantitative analysis will be the identification of underlying reasons regarding the decisions in favour of HD or PD and the provision of different treatment modalities within the dialysis centre. The questionnaire development will be based on the qualitative results, as they will determine the focus of the questionnaire. One aspect of the patient questionnaire will be the decision-making process, with emphasis on the information provided by the treating dialysis physician. The provider questionnaire will focus on attitudes toward the different dialysis modalities and organisational barriers and facilitators. All questionnaires will be pretested by either providers or patients regarding consistency, length and clarity prior to full data collection.

To achieve the highest possible return rate, the survey will be performed in four postal collection waves, following Dillman's 'Total Design Method'. ${ }^{30}$ As an incentive, participating physicians and nurses will receive a financial bonus and participating patients will 
Table 1 Estimated survey participants

\begin{tabular}{lll}
\hline & N & Criteria \\
\hline $\begin{array}{l}\text { Dialysis } \\
\text { patients }\end{array}$ & $\sim 2250$ & $\begin{array}{l}\text { Dialysis onset within the last } \\
\text { 2years; insured by one of the two } \\
\text { cooperating insurance companies } \\
\text { (DAK-Gesundheit and Siemens } \\
\text { Betriebskrankenkasse) }\end{array}$ \\
$\begin{array}{l}\text { Dialysis } \\
\text { physicians }\end{array}$ & $\sim 1200$ & $\begin{array}{l}\text { All German nephrologists working in } \\
\text { an outpatient setting }\end{array}$ \\
$\begin{array}{l}\text { Leading } \\
\text { dialysis } \\
\text { nurses }\end{array}$ & $\sim 700$ & $\begin{array}{l}\text { Head nurses in the } ~ \\
\text { centres in Germany }\end{array}$ \\
$\begin{array}{l}\text { PD-dialysis } \\
\text { nurses }\end{array}$ & $\sim 700$ & $\begin{array}{l}\text { Dialysis nurses, specialising in the } \\
\text { care of PD patients in the } ~ \\
\text { dialysis centres in Germany }\end{array}$ \\
\hline
\end{tabular}

have the chance to take part in a lottery. The data will be captured with Teleform, a software for designing questionnaires and importing data. Psychometric analyses will be performed for factorial validity and reliability to build scales from self-developed instruments. Validated scales will be analysed according to the coding manual. Further information on the estimated survey participants can be found in table 1 . Table 2 gives an overview of the level of information from different data sources.

\section{Patient and public involvement}

Although patients have not been involved in the study design, the patients' view is essential for the project. Therefore, interviews with patients $(n=12)$ are conducted to develop the questionnaires. These interviews will give greater insight into the patients' experiences and needs. Self-help groups for dialysis patients will be approached to discuss the project and get in contact with the patients' perspective.

\section{Ethics and dissemination}

Ethical considerations

The study has been registered with the German Clinical Trials Register. Relevant data protection rules for all analysed data will be enforced. Claims data will be anonymously transmitted by the insurers. The focus groups, as well as the interviews, will be conducted by trained researchers,

Table 2 Data sources with regard to level of information

\section{Data origin and potential information}

\begin{tabular}{|c|c|c|c|c|c|c|}
\hline Level of information & $\mathbf{Z I}$ & $\begin{array}{l}\text { Quality in } \\
\text { nephrology }\end{array}$ & Claims data & $\begin{array}{l}\text { Survey of } \\
\text { physicians }\end{array}$ & $\begin{array}{l}\text { Survey of } \\
\text { nursing staff }\end{array}$ & $\begin{array}{l}\text { Survey of } \\
\text { patients }\end{array}$ \\
\hline Regional influencing factors & Yes & Yes & Yes & - & - & - \\
\hline
\end{tabular}

\begin{tabular}{|c|c|c|c|c|c|c|}
\hline $\begin{array}{l}\text { Influencing factors regarding } \\
\text { nursing staff }\end{array}$ & - & - & - & Yes & Yes & - \\
\hline $\begin{array}{l}\text { Influencing factors regarding } \\
\text { patients }\end{array}$ & $\begin{array}{l}\text { Yes (eg, age, sex, } \\
\text { insurance status, } \\
\text { comorbidities) }\end{array}$ & $\begin{array}{l}\text { Yes (eg, } \\
\text { age, sex, } \\
\text { comorbidities, } \\
\text { nutritional } \\
\text { status, clinical } \\
\text { characteristics) }\end{array}$ & $\begin{array}{l}\text { Yes (eg, } \\
\text { accompanying } \\
\text { disease/s, age, } \\
\text { sex, income, } \\
\text { education) }\end{array}$ & Yes & Yes & Yes \\
\hline
\end{tabular}

\begin{tabular}{|c|c|c|c|c|c|c|}
\hline $\begin{array}{l}\text { Cost comparison of HD and } \\
\text { PD }\end{array}$ & - & - & Yes & - & - & - \\
\hline Advantages & $\begin{array}{l}\text { Data at an } \\
\text { individual patient } \\
\text { level, all patients } \\
\text { insured by } \\
\text { statutory health } \\
\text { insurance in } \\
\text { Germany, all care } \\
\text { providers }\end{array}$ & $\begin{array}{l}\text { Clinical data at } \\
\text { an individual } \\
\text { patient level, } \\
\text { up-to-date } \\
\text { (without delay) }\end{array}$ & $\begin{array}{l}\text { Cross-sectoral } \\
\text { data at an } \\
\text { individual } \\
\text { patient level }\end{array}$ & $\begin{array}{l}\text { Information } \\
\text { about the } \\
\text { physicians' } \\
\text { attitudes and } \\
\text { perspectives }\end{array}$ & $\begin{array}{l}\text { Information } \\
\text { about the } \\
\text { nursing } \\
\text { staff's } \\
\text { attitudes and } \\
\text { perspectives }\end{array}$ & $\begin{array}{l}\text { Information } \\
\text { about the } \\
\text { patients' } \\
\text { attitudes and } \\
\text { perspectives }\end{array}$ \\
\hline Disadvantages & $\begin{array}{l}\text { Not cross- } \\
\text { sectoral, } \\
\text { no clinical } \\
\text { parameters }\end{array}$ & $\begin{array}{l}\text { Only KfH } \\
\text { patients, not } \\
\text { cross-sectoral }\end{array}$ & $\begin{array}{l}\text { No information } \\
\text { about care } \\
\text { providers }\end{array}$ & $\begin{array}{l}\text { Selection } \\
\text { bias (if } \\
\text { applicable) }\end{array}$ & $\begin{array}{l}\text { Selection } \\
\text { bias (if } \\
\text { applicable) }\end{array}$ & $\begin{array}{l}\text { Selection } \\
\text { bias (if } \\
\text { applicable) }\end{array}$ \\
\hline
\end{tabular}


keeping both the patients' psychological stress and the service providers' interests in mind. Written, informed consent will be obtained from all participants in the study, and all study participants will be informed that they may discontinue participation at any given point in time without negative impact. The survey will be performed anonymously. Personal identifiers will be recorded only to manage the responses to the questionnaire. Data import, as well as data analysis, will be completely anonymous. A cognitive pretest on the postal survey will be performed before dissemination of the questionnaire.

\section{Dissemination}

By informing healthcare practitioners, patients and professional organisations and other stakeholders via conferences, scientific and non-scientific publications and seminars, national and international dissemination will be accomplished. Professional exchange and patient participation will be a prominent task within the project in order to achieve the necessary dissemination and sustainability of the research findings. Therefore, a homepage (http://www.maupd.uni-koeln.de/) is being created to spread up-to-date news on the project's progress, and self-help groups will be approached to increase patients' participation. In contacting the major dialysis providers in Germany, an effort will be made to assuage their potential reservations and lay the foundation for further exchange on this topic. Results and experts' contacts are planned to be integrated in a physicians' education platform to reduce professional barriers and support knowledge sharing in PD.

\section{Author affiliations}

${ }^{1}$ Institute of Medical Sociology, Health Services Research and Rehabilitation Science (IMVR), University of Cologne, Faculty of Human Sciences and Faculty of Medicine, Cologne, Germany

${ }^{2}$ Department II of Internal Medicine-QiN Group, University of Cologne, Faculty of Medicine and University Hospital Cologne, Cologne, Germany

${ }^{3}$ Institute of Medical Statistics and Computational Biology (IMSB), University of Cologne, Cologne, Germany

${ }^{4}$ Institute for Health Economics and Clinical Epidemiology (IGKE), University of Cologne, Cologne, Germany

${ }^{5}$ Dr Klaus-Ketzler-Zentrum, KfH-Nierenzentrum, Wiesbaden, Germany

Contributors NS, GVG, TM, SS, UK, HP and MH are applicants of the funded study and designed the study. NS drafted the manuscript with TO and IS, and KR and CS completed the manuscript. The manuscript has been revised and approved by all authors. All authors meet the ICMJE criteria for authorship.

Funding This study is funded by the Innovation Fund of the Federal Joint Committee, the G-BA (Funding No 01VSF16036). The study has passed a peerreview selection process. The sponsor does not have an active role in the study.

Competing interests None declared.

Patient consent for publication Not requierd.

Ethics approval The study has been approved by the Ethics Committee of the Medical Faculty University Hospital of Cologne (17-299) on 25 April 2018.

Provenance and peer review Not commissioned; externally peer reviewed.

Author note The study has been registered with the German Clinical Trials Register (DRKS00012555) and with the German Datenbank Versorgungsforschung Deutschland.

Open access This is an open access article distributed in accordance with the Creative Commons Attribution Non Commercial (CC BY-NC 4.0) license, which permits others to distribute, remix, adapt, build upon this work non-commercially, and license their derivative works on different terms, provided the original work is properly cited, appropriate credit is given, any changes made indicated, and the use is non-commercial. See: http://creativecommons.org/licenses/by-nc/4.0/.

\section{REFERENCES}

1. Potthoff F, Münscher C, Berendes A, et al. Jahresbericht 2016 zur Qualität in der Dialyse. Münster: MNC, 2017.

2. Kwong VW-K, Li PK-T. Peritoneal Dialysis in Asia. Kidney Dis 2015;1:147-56.

3. Li PK, Chow KM, Van de Luijtgaarden MW, et al. Changes in the worldwide epidemiology of peritoneal dialysis. Nat Rev Nephrol 2017;13:90-103.

4. Liu FX, Gao X, Inglese G, et al. A global overview of the impact of peritoneal dialysis first or favored policies: an opinion. Perit Dial Int 2015;35:406-20.

5. Just PM, de Charro FT, Tschosik EA, et al. Reimbursement and economic factors influencing dialysis modality choice around the world. Nephrol Dial Transplant 2008;23:2365-73.

6. Fortnum D, Ludlow M. Improving the uptake of home dialysis in Australia and New Zealand. Ren Soc Australas 2014;10:75-80.

7. Bouvier N, Durand PY, Testa A, et al. Regional discrepancies in peritoneal dialysis utilization in France: the role of the nephrologist's opinion about peritoneal dialysis. Nephrol Dial Transplant 2009;24:1293-7.

8. Sood MM, Tangri N, Hiebert B, et al. Geographic and facility-level variation in the use of peritoneal dialysis in Canada: a cohort study. CMAJ Open 2014;2:E36-44.

9. Walker RC, Marshall MR. Increasing the uptake of peritoneal dialysis in New Zealand: a national survey. J Ren Care 2014;40:40-8.

10. Klein S, et al. Dialyseprävalenz und Versorgung in Deutschland: Bestandsaufnahme und Perspektiven. 2013.

11. Ludlow MJ, George CR, Hawley CM, et al. How Australian nephrologists view home dialysis: results of a national survey. Nephrology 2011;16:446-52.

12. Hingwala J, Diamond J, Tangri N, et al. Underutilization of peritoneal dialysis: the role of the nephrologist's referral pattern. Nephrol Dial Transplant 2013;28:732-40.

13. Merighi JR, Schatell DR, Bragg-Gresham JL, et al. Insights into nephrologist training, clinical practice, and dialysis choice. Hemodial Int 2012;16:242-51.

14. Finkelstein FO, Ezekiel OO, Raducu R. Development of a peritoneal dialysis program. Blood Purif 2011;31(1-3):121-4.

15. Uttley L, Prowant B. Organization of the peritoneal dialysis program - the nurses' role. In: Gokal R, Nolph KD, eds. The Textbook of Peritoneal Dialysis. Dordrecht: Springer, 1994:335-56.

16. Kimura $\mathrm{Y}$, Inoue T, Suzuki H. Role of nurses in a continuous ambulatory peritoneal diagnosis outpatient clinic. Contrib Nephrol 2012;177:64-70.

17. Walker DR, Inglese GW, Sloand JA, et al. Dialysis facility and patient characteristics associated with utilization of home dialysis. Clin J Am Soc Nephrol 2010;5:1649-54.

18. Oliver MJ, Garg AX, Blake PG, et al. Impact of contraindications, barriers to self-care and support on incident peritoneal dialysis utilization. Nephrol Dial Transplant 2010;25:2737-44.

19. Litjens EJ, Mulder WJ, Peppelenbosch NG, et al. Peritoneal dialysis in centenarian patients: no age limitation? J Vasc Access 2016;17(Suppl 1):S53-5.

20. Pajek J. Overcoming the underutilisation of peritoneal dialysis. Biomed Res Int 2015;2015:1-7.

21. Morton RL, Snelling P, Webster AC, et al. Dialysis modality preference of patients with CKD and family caregivers: a discretechoice study. Am J Kidney Dis 2012;60:102-11.

22. European Kidney Patients' Federation (CEAPIR). Pilot European Survey on the treatment of end stage renal disease from the patients' perspective.

23. Robinski M, Mau W, Wienke A, et al. Shared decision-making in chronic kidney disease: a retrospection of recently initiated dialysis patients in Germany. Patient Educ Couns 2016;99:562-70.

24. Lukowsky LR, Mehrotra R, Kheifets L, et al. Comparing mortality of peritoneal and hemodialysis patients in the first 2 years of dialysis therapy: a marginal structural model analysis. Clin J Am Soc Nephrol 2013;8:619-28.

25. Juergensen E, Wuerth D, Finkelstein SH, et al. Hemodialysis and peritoneal dialysis: patients' assessment of their satisfaction with therapy and the impact of the therapy on their lives. Clin J Am Soc Nephrol 2006;1:1191-6. 
26. Kutner NG, Zhang R, Barnhart $\mathrm{H}$, et al. Health status and quality of life reported by incident patients after 1 year on haemodialysis or peritoneal dialysis. Nephrol Dial Transplant 2005;20:2159-67.

27. Chang YT, Hwang JS, Hung SY, et al. Cost-effectiveness of hemodialysis and peritoneal dialysis: A national cohort study with 14 years follow-up and matched for comorbidities and propensity score. Sci Rep 2016;6:30266.
28. Swart E, Gothe H, Geyer S, et al. Gute Praxis Sekundärdatenanalyse (GPS): Leitlinien und Empfehlungen. Gesundheitswesen 2015;77:120-6.

29. Kuckartz U. Qualitative Text analysis: methods, practice, computer assistance. London: Thousand Oaks, 2014.

30. Dillman DA. Mail and telephone surveys: the total design method. New York: Wiley \& Sons, 1978. 